\title{
Comparison of VERION Image-guided System with Manual Marking in Limbal Relaxing Incision to Reduce Astigmatism in Eyes with Cataract
}

\author{
Servet Çetinkaya
}

Department of Ophthalmology, Konyagoz Eye Hospital, Konya, Turkey

\begin{abstract}
Introduction: To compare the results of Verion system with manual marking in the reduction of astigmatism in eyes with cataract and low to moderate astigmatism by forming limbal relaxing incisions (LRIs).

Methods: Thirty-eight eyes of 22 patients who had undergone standard phacoemulsification surgery and limbal relaxing incision for astigmatic correction with the help of image-guided system (Verion) were compared retrospectively with 40 eyes of 24 patients, who had undergone standard phacoemulsification surgery and limbal relaxing incision for astigmatic correction with manual marking.

Results: There was no significant difference between two groups concerning the mean $1^{\text {st }}$ and $6^{\text {th }}$ month postoperative uncorrected visual acuity (UCVA), best-corrected visual acuity (BCVA), spherical and cylindrical values ( $p$-values, 0.054, 0.068, 0.946, $0.957,0.971,0.947,0.254$ and 0.195 , respectively). Even though the mean postoperative $1^{\text {st }}$-month and $6^{\text {th }}$-month cylindrical values of the second group were higher than those of the first group, the difference was not significant statistically.

Discussion and Conclusion: LRIs performed during cataract surgery are efficient in reduction of low to moderate astigmatism. LRIs performed with Verion system seem to be not different significantly from LRIs performed with manual marking in the reduction of astigmatism during cataract surgery.

Keywords: Astigmatism; LRI; manual marking; verion.
\end{abstract}

$\mathrm{R}^{\mathrm{s}}$ efractive cataract surgery is performed to correct both spherical and astigmatic refractive errors. Astigmatism of 1 to 3 diopters has been reported in $15-29 \%$ of eyes with cataract $^{[1-3]}$. Astigmatism during or after cataract surgery can be corrected by spectacles, contact lenses, laser refractive surgery (PRK, LASIK or SMILE), limbal relaxing incisions (LRI), femtosecond laser-assisted corneal arcuate incisions and toric intraocular lens implantation ${ }^{[1,4-6]}$.

The LRI technique involves the placement of incisions cor- responding to the steep meridian, resulting in corneal flattening and the reduction of astigmatic power. LRI is a safe and inexpensive procedure, simple to perform in expert hands, effective in reducing astigmatism up to $4.0 \mathrm{D}$ and resulting in rapid visual rehabilitation ${ }^{[7]}$.

In this study, the LRIs performed with the help of imageguided system (Verion) are compared retrospectively with manual marking in the reduction of astigmatism in eyes with cataract. 


\section{Materials and Methods}

The study protocol was approved by the local ethics committee (Selcuk University, Faculty Medicine Ethics Committee, Konya, Turkey). An informed written consent was obtained from the patients before the surgery. This study was carried out according to the tenets of the Declaration of Helsinki.

Thirty-eight eyes of the 22 patients who had undergone standard phacoemulsification surgery and LRI for astigmatic correction with the help of image-guided system (Verion) between February 2017 and June 2017 comprised Group 1. Forty eyes of 24 patients who had undergone standard phacoemulsification surgery and LRI for astigmatic correction with manual marking between February 2017 and June 2017 comprised Group 2. The mean age of the first group was $59.05 \pm 4.99$ (SD) (52-69) years. Twelve of them (54\%) were males, and 10 of them (46\%) were females. Sixteen of them (72\%) had bilateral and six of them $(28 \%)$ had unilateral cataract. Twelve of the eyes (31\%) had cortical, 12 (31\%) had nuclear and 14 (38\%) had posterior subcapsular cataract. The mean age of the second group was $59.35 \pm 6.49$ (SD) (51-71) years. Twelve of them (50\%) were males and 12 of them (50\%) were females. Sixteen of them had bilateral and eight of them (33\%) had unilateral cataract. Fourteen of the eyes (35\%) had cortical, 12 (30\%) had nuclear and 14 (35\%) had posterior subcapsular cataract. All of the surgeries were performed by a single surgeon (SC).

Biometric measurements of group 1 patients were obtained by the Verion Image-Guided System (Alcon Laboratories, Inc. Fort Worth, TX) (Fig. 1) and those of Group 2 patients were obtained by the IOL Master 500 (Carl Zeiss Meditec, Jena, Germany). Keratometric astigmatisms were measured with an automated keratorefractometer (Topcon KR-8900, Topcon, Japan) preoperatively in all patients and confirmed by biometric measurements.

In Group 1 patients, under topical anesthesia, before starting the phacoemulsification surgery, the video-assisted eye tracking of the Verion Image-Guided system was used to determine the steep meridians of the cornea (Fig. 2). Two LRIs were created with a guarded micrometer diamond blade by forming a groove $1 \mathrm{~mm}$ anterior to the limbus at a depth of $600 \mu \mathrm{m}$ (approximately $80 \%$ of peripheral corneal thickness) with a $6 \mathrm{~mm}$ (in between 1.00 and $2.00 \mathrm{D}$ astigmatism) or $8 \mathrm{~mm}$ (in between 2.00 and $3.00 \mathrm{D}$ astigmatism) length according to Gills nomogram.

In Group 2 patients, manual limbal markings were made at 0 and 180 degrees preoperatively in sitting position at

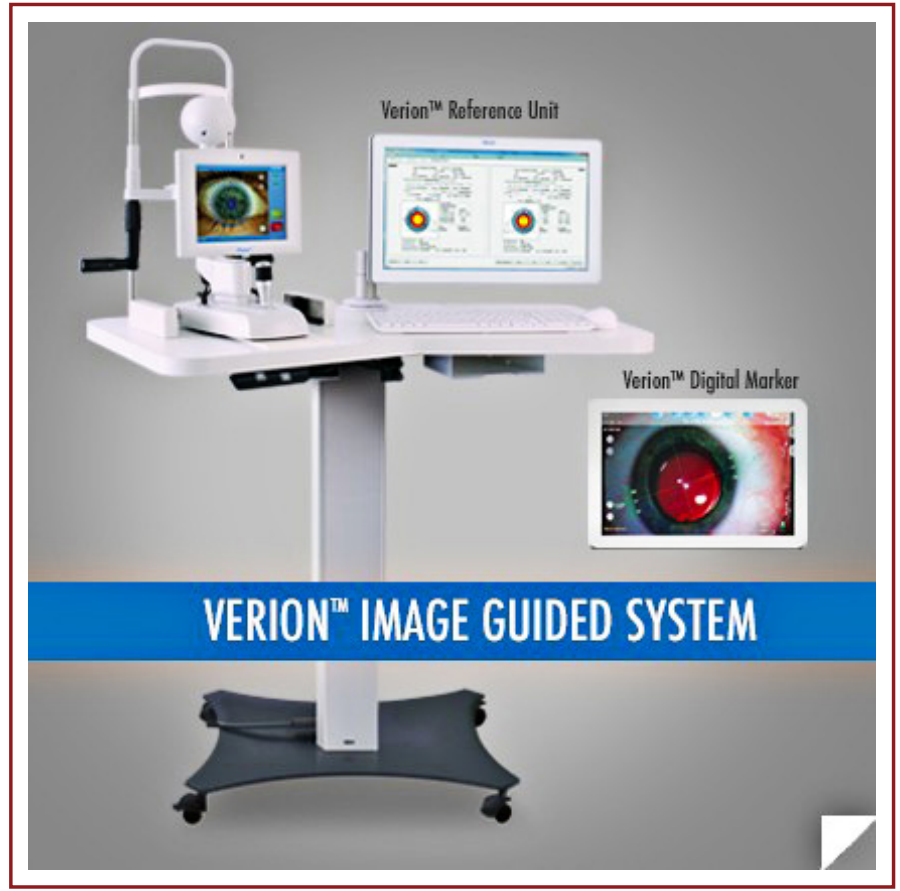

Figure 1. Verion Image-Guided System.

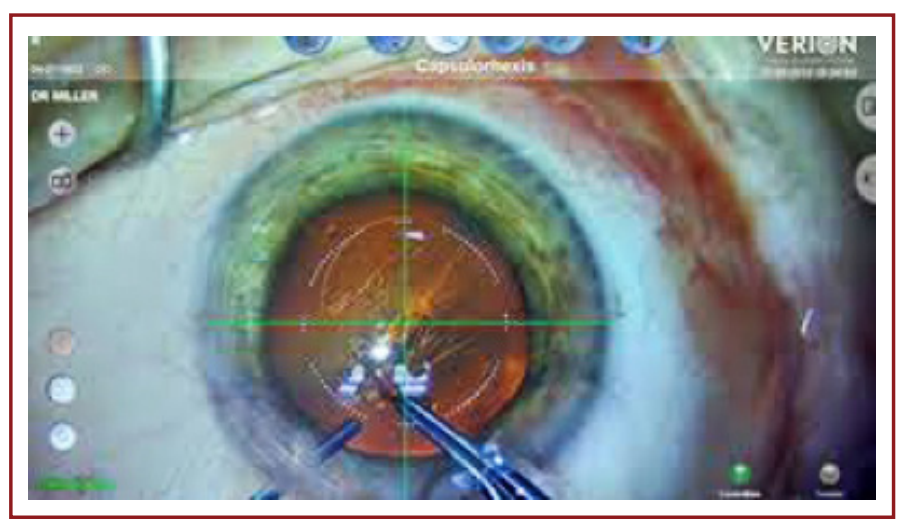

Figure 2. The usage of Verion Image-Guided System.

the slit lamp. The steep meridians were marked using a Mendez ring under topical anestesia before starting the phacoemulsification surgery. Two LRIs were created with a guarded micrometer diamond blade by forming a groove $1 \mathrm{~mm}$ anterior to the limbus at a depth of $600 \mu \mathrm{m}$ (approximately $80 \%$ of peripheral corneal thickness) with a $6 \mathrm{~mm}$ (in between 1.00 and $2.00 \mathrm{D}$ astigmatism) or $8 \mathrm{~mm}$ (in between 2.00 and $3.00 \mathrm{D}$ astigmatism) length according to Gills nomogram. The main incision was temporal in all cases. Monofocal IOLs (Acrysof IQ, Alcon Inc) were implanted in all patients. All of the cases with surgical complications like posterior capsular rupture or vitreous loss were excluded from this study. There was no intraoperative or postoperative complication like keratitis or scar formation, related to LRIs. 
After surgery, patients used topical antibiotic (Moxifloxacin $0.5 \%$, Vigamox, Alcon, USA) four times a day for a week and topical steriod (Dexamethasone Na Phosphate, 0.1\%, Dexa-sine, Liba, USA) six times a day for a week, and it was tapered for subsequent three weeks. Full ophthalmological examinations were performed preoperatively and on $1^{\text {st }}$ day, $1^{\text {st }}$ week, $1^{\text {st }}$ month, $3^{\text {rd }}$ month and 6 th month after the operation. Keratometric astigmatisms were measured with an automated keratorefractometer (Topcon KR-8900, Topcon, Japan) postoperatively in all patients.

For statistical analysis, SPSS version 22 programme was used. The skewness and kurtosis values of the variables were between -1 and +1 , but additionally Normality of Distribution (Shapiro-Wilks) test was performed and $\mathrm{p}$ values were greater than 0.05 for all variables, it showed that the distribution was normal and similar between the two groups. For comparison of percentage of sex between the two groups, Chi-square test was used. For comparison of data inside the groups, paired t-test and between the groups, t-test was used. A $p<0.05$ value was accepted as statistically significant.

\section{Results}

Concerning age, sex, laterality and type of cataract, there was no significant difference between two groups ( $p$-val- ues, $0.910,0.884,0.895$ and 0.756 , respectively). There was no significant difference between two groups in respect to the mean preoperative uncorrected visual acuity (UCVA), best-corrected visual acuity (BCVA), spherical and cylindrical values ( $p$-values, $0.842,0.841,0.165$ and 0.858 , respectively). The preoperative characteristics of the patients are summarized in Table 1.

There was no significant difference between two groups regarding the mean $1^{\text {st }}$ and $6^{\text {th }}$ month postoperative UCVA, $B C V A$, spherical and cylindrical values ( $p$-values, 0.054, $0.068,0.946,0.957,0.971,0.947,0.254$ and 0.195 , respectively). Even though the mean postoperative 1st-month and 6th-month cylindrical values of the second group were higher than those of the first group, the difference was not significant statistically. The postperative characteristics of the patients are summarized in Table 2 .

\section{Discussion}

Astigmatism is an important refractive disorder. To obtain satisfactory postoperative results, astigmatism should be decreased as far as possible. Different surgical techniques have been developed to minimize astigmatism during cataract surgery. LRI, femtosecond laser-assisted corneal arcuate incisions, and toric intraocular lens implantation are the choices for correction of astigmatism during cataract

Table 1. Preoperative characteristics of the patients

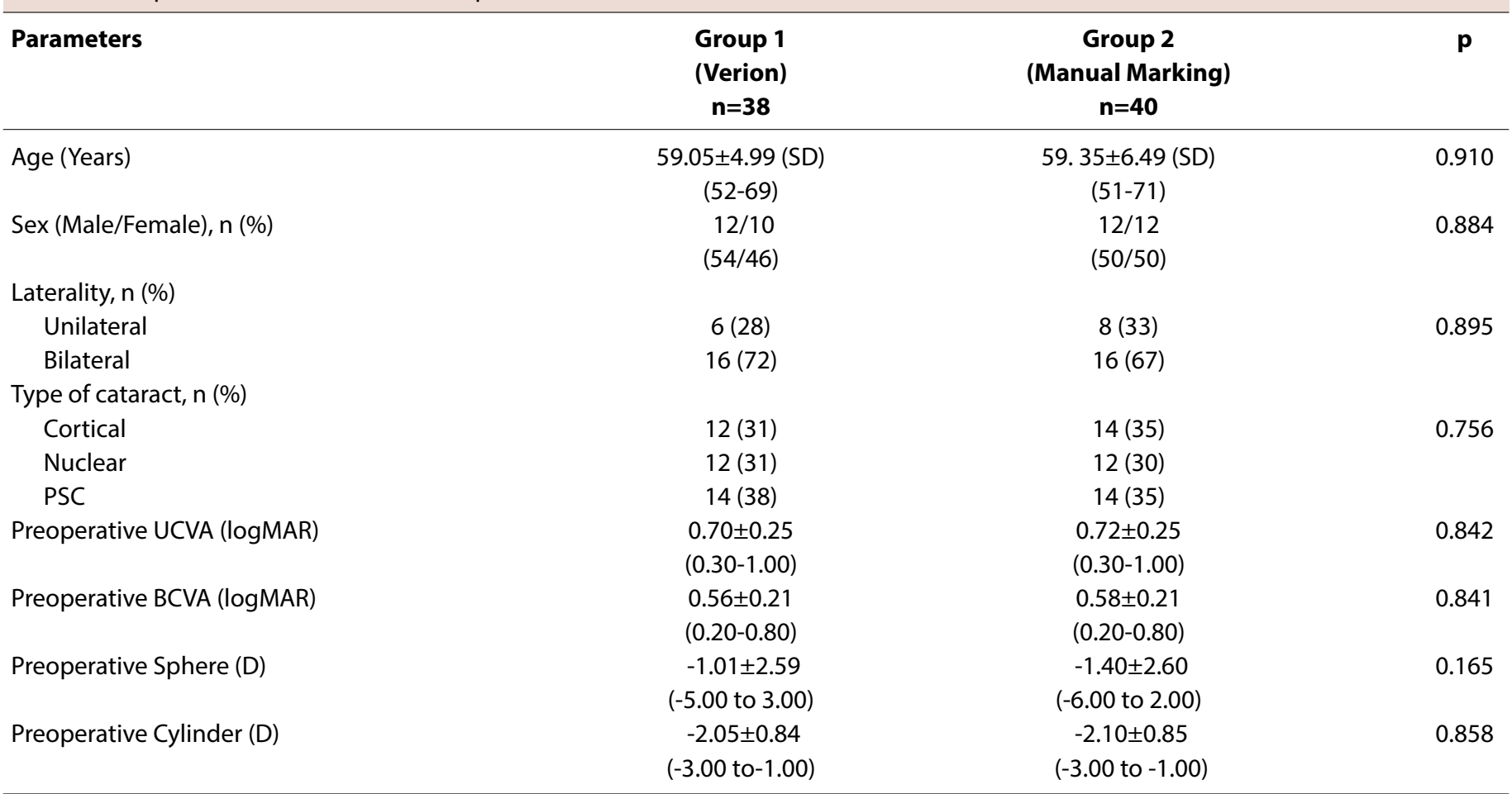

PSC; posterior subcapsular cataract, UCVA; uncorrected visual acuity, BCVA; corrected visual acuity, D; Diopter, SD; standard deviation. 
Table 2. Postoperative characteristics of the patients

\begin{tabular}{|c|c|c|c|}
\hline Parameters & $\begin{array}{c}\text { Group } 1 \\
\text { (Verion) } \\
n=38\end{array}$ & $\begin{array}{c}\text { Group } 2 \\
\text { (Manual Marking) } \\
\mathrm{n}=\mathbf{4 0}\end{array}$ & $\mathbf{p}$ \\
\hline Postoperative 1 month, UCVA (logMAR) & $\begin{array}{c}0.24 \pm 0.01(\mathrm{SD}) \\
(0.00-0.040)\end{array}$ & $\begin{array}{c}0.31 \pm 0.55(\mathrm{SD}) \\
(0.00-0.50)\end{array}$ & 0.054 \\
\hline Postoperative 6 month, UCVA (logMAR) & $\begin{array}{c}0.19 \pm 0.12 \\
(0.00-0.30)\end{array}$ & $\begin{array}{c}0.25 \pm 0.11 \\
(0.00-0.40)\end{array}$ & 0.068 \\
\hline Postoperative 1 month, BCVA (logMAR) & $\begin{array}{c}0.01 \pm 0.03 \\
(0.00-10)\end{array}$ & $\begin{array}{c}0.01 \pm 0.03 \\
(0.00-0.10)\end{array}$ & 0.957 \\
\hline Postoperative 6 month, BCVA (logMAR) & $\begin{array}{c}0.01 \pm 0.03 \\
(0.00-10)\end{array}$ & $\begin{array}{c}0.01 \pm 0.03 \\
(0.00-0.10)\end{array}$ & 0.165 \\
\hline Postoperative 1 month, Sphere (D) & $\begin{array}{c}-0.10 \pm 0.48 \\
(-1.00 \text { to } 1.00)\end{array}$ & $\begin{array}{c}-0.10 \pm 0.44 \\
(-1.00 \text { to } 1.00)\end{array}$ & 0.971 \\
\hline Postoperative 6 month, Sphere (D) & $\begin{array}{c}-0.07 \pm 0.18 \\
(-0.50 \text { to } 0.000)\end{array}$ & $\begin{array}{c}-0.07 \pm 0.18 \\
(-0.50 \text { to } 0.00)\end{array}$ & 0.947 \\
\hline Postoperative 1 month, Cylinder (D) & $\begin{array}{c}-1.15 \pm 0.37 \\
(-1.50 \text { to- } 0.50)\end{array}$ & $\begin{array}{c}-1.30 \pm 0.25 \\
(-1.50 \text { to }-1.00)\end{array}$ & 0.254 \\
\hline Postoperative 6 month, Cylinder (D) & $\begin{array}{c}-0.97 \pm 0.51 \\
(-1.5 \text { to- } 0.50)\end{array}$ & $\begin{array}{c}-1.15 \pm 0.27 \\
(-1.50 \text { to }-1.00)\end{array}$ & 0.195 \\
\hline
\end{tabular}

UCVA; uncorrected visual acuity, BCVA; best-corrected visual acuity, D; Diopter, SD: Standard deviation.

surgery ${ }^{[8-10]}$. The LRI has been considered to be a safe and effective technique with reduced intraoperative and postoperative complications ${ }^{[11]}$.

In this study, we compared the LRIs performed with the help of Verion image-guided system and with manual marking in the reduction of astigmatism during cataract surgery. There was no significant difference between two groups with respect to postoperative UCVA and BCVA values. Although the mean postoperative 1st and 6th months cylindrical values of the second group (manual marking group) were higher than those of the first group (Verion group), the difference was not significant statistically. The mean postoperative cylindrical values of both groups were significantly lower than preoperative values.

In the literature, we have seen studies on effectiveness of LRI, comparison of LRI with toric IOL implantation, comparison of keratometric and biometric measurements obtained by Verion image-guided system with optical biometry and auto-keratorefractometer; however, to our knowledge we did not encounter any study on comparison of LRI performed with Verion system and manual marking for correction of astigmatism during cataract surgery or any study on effectiveness of LRI performed with Verion system.

Lam et al. ${ }^{[12]}$ reported that both toric IOL implantation and $\mathrm{LRI}$ were effective in correcting corneal astigmatism $\leq 3 \mathrm{D}$ during phacoemulsification, while LRI tended to undercorrect astigmatism. Coloma-Gonzalez et al. ${ }^{[13]}$ reported that LRI is a simple, safe and effective method not only for reducing preexisting astigmatism during cataract surgery but also in providing good unaided visual acuity. Roman et al. ${ }^{[14]}$ reported that limbal relaxing incisions are an effective and simple approach to the correction of significant preoperative astigmatism during cataract surgery. Loncar et al. ${ }^{[15]}$ reported that limbal relaxing incisions provide a viable option for correcting pre-existing astigmatism at the time of cataract surgery with mild complications. Lim et al. ${ }^{[16]}$ reported that the keratometric effects of LRIs were stable from 10 weeks to 3 years postoperatively. Carvalho et al. ${ }^{[17]}$ reported that limbal relaxing incisions performed during phacoemulsification surgery appear to be a safe, effective and stable procedure to reduce pre-existing corneal astigmatism.

\section{Conclusion}

In conclusion, LRIs performed during cataract surgery are efficient in the reduction of low to moderate astigmatism. LRIs performed with Verion system seem to be not different significantly from LRIs performed with manual marking in the reduction of astigmatism during cataract surgery.

Ethics Committee Approval: The Ethics Committee of Selçuk University Faculty of Medicine provided the ethics committee approval for this study (20.12.2017-2017/377).

Peer-review: Externally peer-reviewed.

Conflict of Interest: None declared. 
Financial Disclosure: The author declared that this study received no financial support.

\section{References}

1. Mohammad-Rabei $H$, Mohammad-Rabei E, Espandar G, Javadi MA, Jafarinasab MR, Hashemian SJ, et al. Three Methods for Correction of Astigmatism during Phacoemulsification. J Ophthalmic Vis Res 2016;11:162-7. [CrossRef]

2. Brint SF. Refractive cataract surgery. Int Ophthalmol Clin 1994;34:1-11. [CrossRef]

3. Zare MA, Tehrani MH, Gohari M, Jabbarvand M, Hashemian M, Mohammadpour $M$, et al. Management of corneal astigmatism by limbal relaxing incisions during cataract surgery. Iran J Ophthalmal 2010,22:15-20.

4. Li Z, Han Y, Hu B, Du H, Hao G, Chen X. Effect of Limbal relaxing incisions during implantable collamer lens surgery. BMC Ophthalmol 2017;17:63. [CrossRef]

5. Blehm C, Potvin R. Pseudophakic astigmatism reduction with femtosecond laser-assisted corneal arcuate incisions: a pilot study. Clin Ophthalmol 2017;11:201-7. [CrossRef]

6. American Academy of Ophthalmology. Jick SL, Beardsley TL, Brasington CR, Buznego C, Grostern RJ, Park L, et al. Surgery for cataract. Lens and Cataract 2016-2017; 2016. p.123-4.

7. Leon P, Pastore MR, Zanei A, Umari I, Messai M, Negro C, et al. Correction of low corneal astigmatism in cataract surgery. Int J Ophthalmol 2015;8:719-24.

8. Güell JL, Vazquez M. Correction of high astigmatism with astigmatic keratotomy combined with laser in situ keratomileusis. J Cataract Refract Surg 2000;26:960-6. [CrossRef]

9. Rubenstein JB, Raciti M. Approaches to corneal astigmatism in cataract surgery. Curr Opin Ophthalmol 2013;24:30-4. [CrossRef] 10. Poll JT, Wang L, Koch DD, Weikert MP. Correction of astigmatism during cataract surgery: toric intraocular lens compared to peripheral corneal relaxing incisions. J Refract Surg 2011;27:165-71. [CrossRef]

11. Kaufmann C, Peter J, Ooi K, Phipps S, Cooper P, Goggin M; Queen Elizabeth Astigmatism Study Group. Limbal relaxing incisions versus on-axis incisions to reduce corneal astigmatism at the time of cataract surgery. J Cataract Refract Surg 2005;31:2261-5. [CrossRef]

12. Lam DK, Chow VW, Ye C, Ng PK, Wang Z, Jhanji V. Comparative evaluation of aspheric toric intraocular lens implantation and limbal relaxing incisions in eyes with cataracts and $\leq 3$ dioptres of astigmatism. Br J Ophthalmol 2016;100:258-62. [CrossRef]

13. Coloma-González I, González-Herrera M, Mengual-Verdú E, Hueso-Abancens JR. [Limbal relaxing incisions and cataract surgery: our experience]. [Article in Spanish]. Arch Soc Esp Oftalmol 2007;82:551-4. [CrossRef]

14. Roman S, Auclin F, Baudouin C. [Limbal relaxing incisions to correct preexisting astigmatism during cataract surgery]. [Article in French]. J Fr Ophtalmol 2009;32:390-5.

15. Loncar VL, Vicković IPIveković R, Mandić Z. Limbal relaxing incision during cataract surgery. Acta Clin Croat 2012;51:28992.

16. Lim R, Borasio E, Ilari L. Long-term stability of keratometric astigmatism after limbal relaxing incisions. J Cataract Refract Surg 2014;40:1676-81. [CrossRef]

17. Carvalho MJ, Suzuki SH, Freitas LL, Branco BC, Schor P, Lima $A L$. Limbal relaxing incisions to correct corneal astigmatism during phacoemulsification. J Refract Surg 2007;23:499-504. 